các nhóm có nhiều triệu chứng và yếu tố nguy cơ. Các bệnh nhân có nhiều đợt cấp, phải nhập viện nhiều lần có nguy cơ SDD cao, liên quan đển nhiều cơ chế bệnh sinh của bệnh. Vì vậy, việc tư vấn và can thiệp dinh dướng cho các bệnh nhân này rất quan trọng, giúp dự phòng và cải thiện tình trạng $S D D$, góp phân điêu trị và quản lý hiệu quả BN BPTNMT.

\section{KẾT LUẬN}

Các bệnh nhân BPTNMT trong đợt cấp nhập viện thường có nguy cơ SDD. Tình trạng SDD có mối liên quan đến đặc điểm phân nhóm bệnh nhân BPTNMT, với tỷ lệ SDD tăng lên theo mức độ nặng của BPTNMT.

\section{TÀI LIÊU THAM KHẢO}

1. Global initiative for Chronic obstructive lung disease (2020), "Global strategy for the diagnosis, management, and prevention of chronic obstructive pulmonary disease 2020 report".

2. World Health Organization technical report series (1995), "Physical status: the use and interpretation of anthropometry. Report of a WHO Expert Committee", 854, 1-452.

3. Guigoz Y., Vellas B., Garry P. J. (1996), "Assessing the nutritional status of the elderly: The
Mini Nutritional Assessment as part of the geriatric evaluation", Nutrition reviews, 54(1 Pt 2), 59-65.

4. Detsky A. S., McLaughlin J. R., Baker J. P., et al. (1987), "What is subjective global assessment of nutritional status?", JPEN. Journal of parenteral and enteral nutrition, 11(1), 8-13.

5. Nguyễn Đức Long (2014), "Khảo sát tình trạng dinh dưỡng và nhận xét chế độ dinh dưỡng đang sử dụng ở bệnh nhân đợt cấp bệnh phổi tắc nghẽn mạn tính", Luận văn Thạc sỹ y học, ĐH Y Hà Nội.

6. Gupta B., Kant S., Mishra R., et al. (2010), "Nutritional status of chronic obstructive pulmonary disease patients admitted in hospital with acute exacerbation", Journal of clinical medicine research, 2(2), 68-74.

7. Dilek K., Ozgur O., Say S.D., et al. (2018), "Factors associated with current smoking in COPD patients:A cross-sectional study from the Eastern Black Sea region of Turkey", Tobacco induced diseases, 16, 22-22.

8. Bùi Mỹ Hanh (2020), "Các yếu tố liên quan đến kết quả điểu trị đớt cấp bênh phổi tắc nghẽn man tính, một phân tích thời gian phục hồi", Tạp chí nghiên cứu y học, 10, 133-141.

9. Yuceege M.B. (2013), "The evaluation of nutrition in male COPD patients using subjective global assesment and mini nutritional assesment", International Journal of Internal Medicine 2013, 2(1), 1-5.

\title{
ĐĂC ĐIỂM XƯƠNG TRÊN HÌNH ẢNH CẮT LỚP CHÙM TIA HÌNH NÓN CỦA BÊNH NHÂN RỐI LOAN THÁI DƯƠNG HÀM VÀ MỐI TƯƠNG QUAN VỚI TRIÊUU CHỨNG LÂM SÀNG
}

\author{
Nguyễn Văn Tâm ${ }^{1}$, Nguyễn Thị Thu Phương², Nguyễn Thị Thúy Nga ${ }^{3}$
}

\section{TÓM TẮT}

Muc tiêu: Khảo sát các đăc điểm xương và đánh giá mối tương quan giữa các thay đổi xương với triệu chứng lâm sàng của bệnh nhân rối loạn thái dương hàm. Đối tượng và phương pháp: 98 bệnh nhân rối loạn thái dương hàm chẩn đoán theo tiêu chuẩn DC/TMD năm 2014 được chia thành ba nhóm: rối loạn cớ, rối loạn khớp và nhóm phức hợp (có cả rối loạn cớ và rối loạn khớp). Mỗi bệnh nhân được thăm khám lâm sàng (tình trạng đau khớp, tiếng kêu khớp, hạn chế há miệng), chụp phim CBCT khớp để đánh giá các đặc điểm xương của lồi cầu xương hàm dưới. Kết quả: $31.6 \%$ đối tượng nghiên cứu không có tổn thương xương; $39.2 \%$ có mòn xương; $28.6 \%$ có

\footnotetext{
1 Trường Đại hoc Y Hà Nôii

2 Viện Đào tạo Răng Hàm Mặt-Trường đại học Y Hà Nội ${ }^{3} B$ ềnh viện Răng Hàm Mặt Trung ương Hà Nội

Chịu trách nhiệm chính: Nguyễn Văn Tâm

Email: nguyenvantam110395@gmail.com

Ngày nhận bài: 12.5.2021

Ngày phản biên khoa hoc: 5.7.2021

Ngày duyệt bài: 14.7.2021
}

phẳng bề mặt khớp; $23.7 \%$ có gai xương; $11.3 \%$ có xơ xương dưới sun và $8.2 \%$ có nang xương dưới sun. Triệu chứng đau khớp có tương quan với các tổn thương nang dưới sụn $(r=0.264)$, gai xương ( $r=0.446)$ và mòn xương ( $r=0.34)$; tiếng kêu khớp có tương quan với xơ xương dưới sụn $(r=0.278)$; há miệng hạn chế có tương quan với gai xương $(r=0.278)$. Cả ba triêu chứng được khảo sát đều không có tương quan với phẳng bề mặt khớp. Kết luận: Mòn xương, xơ xương dưới sụn và gai xương là các đặc điểm có giá trị trong chẩn đoán thoái hóa khớp.

Tư khóa: Rối loan thái dương hàm, khớp thái dương hàm, phim cắt lớp chùm tia hình nón (CBCT).

\section{SUMMARY}

OSSEOUS CHARACTERISTICS BY CONE BEAM COMPUTED TOMOGRAPHY IMAGING IN PATIENTS WITH TEMPOROMANDIBULAR DISORDERS AND CORRELATION WITH CLINICAL FINDINGS

Objectives: To evaluate the condylar osseous characteristics by Cone Beam computed tomography (CBCT) and to investigated the its correlation with 
clinical finding in patients with temporomandibular disorders. Subjects and methods: 98 diagnosed TMD patients according to the DC/TMD 2014 was divided into 3 groups: Muscle disorders, Joint Disorders and Complex group. Clinical observations (joint pain, joint sound, limited opening) were recorded, CBCT were perfomed to evaluate the bone changes of mandibular condyle. Results: $31.6 \%$ subjects have no alteration; $39.2 \%$ have erosion of the condyle; $28.6 \%$ have flattening, $23.7 \%$ have osteophyte fomation; $11.3 \%$ have subchondral sclerosis and $8.2 \%$ have subchondral cyst. There were significant correlations between joint pain and subchondral cyst $(r=0,264)$, osteophyte formation ( $r=$ $0.446)$, erosion of the condyle $(r=0.34)$; joint sound and subchondral sclerosis $(r=0.278)$; limited opening and osteophyte formation $(r=0.278)$. Conclusion: Condylar erosion, subchondral sclerosis and osteophyte formation are valuable characteristics in diagnosing joint disorders.

Keywords: Temporomandibular disorders, Temporomandibular joint, CBCT.

\section{I. ĐẶT VẤN ĐỀ}

Rối loạn thái dương hàm (Temporomandibular Disorder-TMD) là một nhóm các rối loạn phức tạp ảnh hưởng đến khớp thái dương hàm, các cơ nhai và/ hoặc các cấu trúc liên quan, được xác định là một nguyên nhân chính gây ra đau không do răng ở vùng hàm mặt ${ }^{1}$. Ơ Việt Nam, nghiên cứu của Phạm Như Hải (2006) trên 544 người dân Hà Nội cho thây số người có biểu hiện rối loạn từ trung bình đến nặng chiếm 20.6\%. Nghiên cứu của Đoàn Hồng Phượng, Hoàng Tử Hùng ${ }^{3}$ trên 780 người dân sống tại 6 quân thành phố Hồ Chí Minh cho thấy 64,87\% người dân có TMD.

Biểu hiện lâm sàng của TMD rất phong phú và thay đổi ở từng người bệnh ${ }^{4}$. Những thay đổi trên xương được phát hiện nhờ Xquang với phim cắt lớp chùm tia hình nón (CBCT) là một kĩ thuật được ưu tiên lựa chọn vì nó cung cấp hình ảnh ba chiều, không chồng bóng, cho chất lượng chẩn đoán cao, và liều phóng xạ thấp hơn so với phim cắt lớp vi tính ${ }^{5}$. Tại Việt Nam, ứng dụng $\mathrm{CBCT}$ vào chẩn đoán TMD còn chưa phổ biến, các nghiên cứu về vấn đề này còn chưa nhiều. Vì vậy, nghiên cứu này được tiến hành với các mục tiêu:

1. Mô tả đắc điểm xương trền hình ảnh cắt lớp chùm tia hinh nón của bênh nhân rôi loạn thái dương hàm.

2. Đánh giá môi tương quan giữa các thay đôi xương với triệu chứng lâm sàng ở nhóm bệnh nhân trên.

\section{II. ĐỐl TƯỢNG VÀ PHƯƠNG PHÁP NGHIÊN CỨU}

Đối tượng nghiên cứu. Nghiên cứu được thực hiện trên những bệnh nhân TMD tại khoa Nắn chỉnh răng Bệnh viện Răng Hàm Mặt Trung Ương Hà Nội và Viện đào tạo Răng hàm mặt, trường Đại học Y Hà Nội.

\section{Tiêu chuẩn lưa chon.}

- Bênh nhân TMD được chẩn đoán theo tiêu chuẩn DC/TMD năm 2014: chia thành 3 nhóm rối loạn cơ, rối loạn khớp và nhóm phức hợp (có cả rối loạn cơ và rối loạn khớp).

- Có đây đủ phim cắt lớp chùm tia hình nón (CBCT).

\section{Tiêu chuân loai trù:}

- Đau vùng hàm mặt do các nguyên nhân khác: đau do răng, viêm nhiễm cấp tính, đau dây thần kinh số $\mathrm{V}$, chấn thương, ...

- Những bệnh nhân đang có bệnh lý toàn thân chưa được điều trị ổn định: cao huyết áp, tim mạch, đái tháo đường, tâm thần, ...

Phương pháp nghiên cứu

Thiết kế nghiên cứu: nghiên cứu mô tả cắt ngang

Cõ mẫu: 98 bênh nhâm

Phương pháp chọn mẫu: mẫu thuận tiện

Thu thập số liệu. Khám lâm sàng: Xác định tình trạng đau khớp, tiếng kêu khớp và hạn chễ há miệng (biên độ há miệng <40mm)

Chup CBCT khớp thái dương hàm: Xác đinh các đặc điểm về xương của lồi cầu xương hàm dưới. Các thay đổi xương trên phim CBCT được đánh giá theo 5 đăc điểm sau đây: xơ xương dưới sụn của lồi câu, gai xương, mòn xương ở lồi cầu, nang dưới sụn, phẳng bề mặt khớp của lồi câu. Các đặc điểm này được đánh giá có hay không xuất hiện.

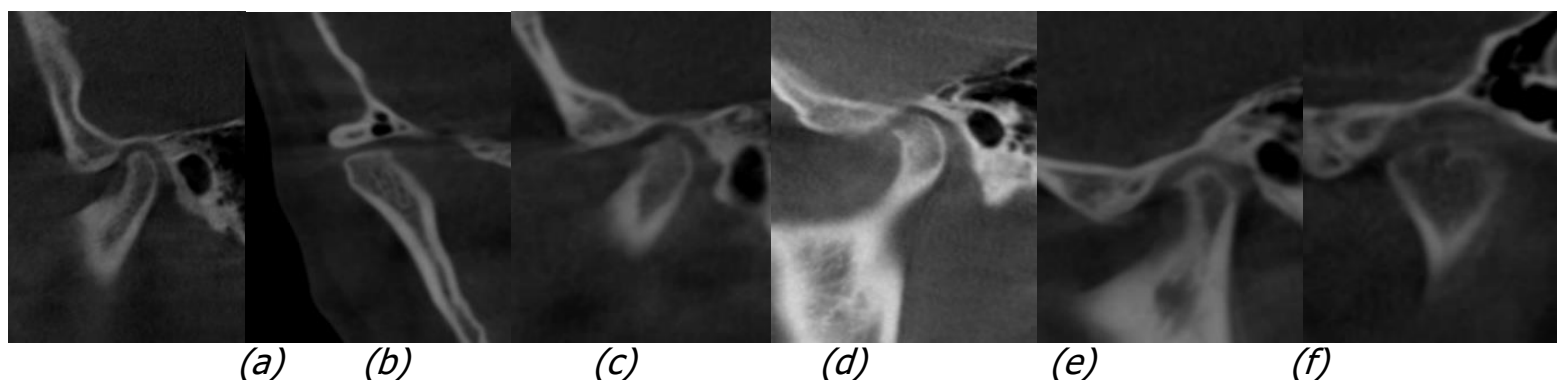

Hinh 1: Đặc điểm xương trên CBCT (a) không có tổn thương, (b) phăng bề mạt khớp, (c) xơ xương dưới sụn, (d) mòn xương, (e) gai xương, ( $f$ ) nang dưới sưn 
Phương pháp xử lý số liệu. Số liệu được nhập và xử lý bằng phần mềm SPSS 16.0

- Thống kê mô tả: tỷ lệ \% các đặc điểm xương.

- Hồi quy logistic: đánh giá tương quan giữa các thay đổi về xương với triệu chứng lâm sàng

\section{KẾT QUẢ NGHIÊN CỨU}

Đặc điểm xương trên phim CBCT của người bệnh TMD. Trong các đối tượng nghiên cứu, có 31 đối tượng không có tổn thương chiếm $31.6 \%$; 38 đối tượng có mòn xương chiếm $39.2 \%$; 28 đối tượng có phẳng bề mặt khớp chiếm $28.6 \%, 23$ đối tượng có gai xương chiếm 23.7\%; có 11 đối tượng có xơ xương dưới sụn chiếm $11.3 \%$ và 8 đối tượng có nang xương dưới sụn chiếm $8.2 \%$. Trong nhóm rối loạn cơ, $70 \%$ đối tượng không có tổn thương và $30 \%$ đối tượng có phẳng bề mặt khớp, không xuất hiện các đặc điểm còn lại. Trong nhóm rối loạn khớp và nhóm phức hợp, mòn xương là tổn thương xuất hiện với tỉ lệ cao nhất, lần lượt là $50 \%$ và $61.8 \%$; sau đó đến gai xương với $35.3 \%$ và $32.4 \%$.

Sự khác biệt về các đặc điểm không có tổn thương, xơ xương dưới sụn, mòn xương và gai xương là có ý nghĩa thống kê $(p<0.05$, kiểm định $\chi^{2}$ ). Trong khi đó, sự khác biệt về các đặc điểm phẳng bề mặt khớp và nang dưới sụn là không có ý nghĩa thống kê ( $p>0.05$, kiểm định $\left.\chi^{2}\right)$.

Mối tương quan giữa một số đặc điểm lâm sàng với sự thay đổi xương trên nhóm đối tượng nghiên cứu

Trong nhóm đối tượng nghiên cứu, triệu chứng đau khớp có tương quan với các tổn thương nang dưới sụn, gai xương và mòn xương, trong đó tương quan tổn thương gai xương và mòn xương ở mức trung bình với hệ số tương quan $r$ lân lượt là 0.446 và 0.34 và với tổn thương nang dưới sụn ở mức tương quan yếu với hệ số tương quan r là 0.264 .

Triệu chứng tiếng kêu khớp có tương quan yếu với tổn thương xơ xương dưới sụn với hệ số tương quan $r$ là 0.278 . Triệu chứng há miệng hạn chế có tương quan yếu với tổn thương gai xương với hệ số tương quan $r$ là 0.278. Cả ba triệu chứng được khảo sát đều không có tương quan với phẳng bề mặt khớp.

\section{BÀN LUẬN}

Trong 98 đối tượng nghiên cứu, có $31.6 \%$ đối tượng không có tổn thương xương, $39.2 \%$ đối tượng có mòn xương, 28.6\% đối tượng có phẳng bề mặt khớp, $23.7 \%$ đối tượng có gai xương, có $11.3 \%$ đối tượng có xơ xương dưới sụn và $8.2 \%$ đối tượng có nang xương dưới sụn. Kết quả này tương đồng với nghiên cứu của tác giả Mani' .

Theo Barghan $\mathrm{S}^{5}$, nang dưới sụn là một trong các tổn thương của một khớp thoái hóa. Tuy nhiên, trong nghiên cứu của chúng tôi, đặc điểm này xuất hiện với tỉ lệ thấp, chiếm $8.2 \%$.

Trong nhóm đối tượng nghiên cứu, triệu chứng há miệng hạn chế có tương quan yếu với tổn thương gai xương. Triệu chứng đau khớp có tương quan với các tổn thương nang dưới sụn, gai xương và mòn xương, và với tổn thương nang dưới sụn ở mức tương quan yếu. Triệu chứng tiếng kêu khớp có tương quan yếu với tổn thương xơ xương dưới sụn. Kết quả này không tương đồng với nghiên cứu của Arayasantiparb 7 , trong đó triệu chứng đau khớp không có tương quan đáng kể với các thay đổi xương, nhưng triệu chứng tiếng kêu khớp có tương quan đáng kể với bốn đặc điểm xơ xương, mòn xương, gai xương và nang dưới sụn. Điều này có thể do nhóm đối tượng nghiên cứu của Arayasantiparb là các bệnh nhân được chẩn đoán thoái hóa khớp, mà không đánh giá các nhóm rối loạn khác của TMD.

Cả ba triệu chứng được khảo sát đều không có tương quan với phẳng bề mặt khớp. Điều này gợi ý rằng phẳng bề mặt khớp là một đặc điểm gặp ở các khớp khỏe mạnh hoặc ít nhất là không có triệu chứng. Các đặc điểm xỡ xương dưới sụn, mòn xương, gai xương là các tổn thương có giá trị chẩn đoán rối loạn khớp.

\section{KẾT LUẬN}

Trên phim $\mathrm{CBCT}$, các đặc điểm xơ xương dưới sụn, mòn xương, gai xương là các tổn thương có giá trị chẩn đoán rối loạn khớp, trong khi đó phẳng bề mặt khớp là một đặc điểm có thể gặp ở các khớp khỏe mạnh hoặc ít nhất là không có triệu chứng. Trong nhóm đối tượng nghiên cứu, triệu chứng há miệng hạn chế có tương quan yếu với tổn thương gai xương; đau khớp có tương quan với các tổn thương nang dưới sụn, gai xương và mòn xương, trong đó tương quan tổn thương gai xương và mòn xương; tiếng kêu khớp có tương quan yếu với tổn thương xơ xương dưới sụn. Chúng tôi đề nghị rằng nên sử dụng $\mathrm{CBCT}$ thay vì các kĩ thuật X-quang khác để khảo sát mô xương của khớp thái dương hàm, từ đó đưa ra chẩn đoán chính xác, lập kế hoạch điều trị thích hợp và tiên lượng được cho từng bệnh nhân.

\section{TÀI LIỆU THAM KHẢO}

1. Leeuw R de, Klasser GD, American Academy of Orofacial Pain, eds. Orofacial Pain: Guidelines for Assessment, Diagnosis, and Management. Sixth 
edition. Quintessence Publishing Co, Inc; 2018, 104-144.

2. Phạm Như Hải. Nghiên Cứu Dịch Tễ Học Loạn Năng Bộ Máy Nhai và Đề Xuất Giải Pháp Can Thiệp, Luận an Tiến sỹ $Y$ học, Trường Đại học $Y$ Hà Nội; 2006.

3. Đoàn Hồng Phượng, Hoàng Tử Hùng. Tình hình rối loạn thái dương hàm ở người lớn (18 - 54 tuổi) tại thành phố Hồ Chí Minh, Y học thành phố Hồ Chí Minh, 11(2), $32-40$.

4. Okeson J. Management of Temporomandibular Disorders and Occlusion. Seventh edition. Mosby; 2013, 1-250.
5. Barghan S, Merrill R, Tetradis S. Cone beam computed tomography imaging in the evaluation of the temporomandibular joint. J Calif Dent Assoc. 2010;38(1):33-39.

6. Mani F. và Sivasubramanian S. A study of temporomandibular joint osteoarthritis using computed tomographic imaging. Biomed J. 2016; 39.

7. Arayasantiparb R., Mitrirattanakul S., Kunasarapun P., et al. Association of radiographic and clinical findings in patients with temporomandibular joints osseous alteration. Clin Oral Investig. 2020; 24, 221-227.

\section{ĐĂC ĐIỂM LÂM SÀNG, CÂN LÂM SÀNG TIÊU CHẢY CẤP PHÂN MÁU Ở TRẺ EM TẠI BỆNH VIỆN ĐA KHOA ĐỨC GIANG}

\section{TÓM TẮT}

Tiêu chảy cấp phân máu là tình trạng nhiễm khuẩn đường tiêu hóa thường gặp ở trẻ em, gây ảnh hưởng đến sự phát triển của tré. Mục tiêu nghiên cứu: mố tả đặc điểm lâm sàng, cân lâm sàng tiêu chảy cấp phân máu ở trẻ em. Đối tượng và phương pháp nghiên cứu: Nghiên cứu tiến cứu mô tả một loạt ca bểnh gồm 64 bênh nhân được chẩn đoán tiêu chảy cẩp phân máu vào điều trị tai khoa Nhi bênh viên đa khoa Đức Giang từ tháng 08/2020 đến tháng 05/2021. Kết quả: Tuổi trung bình mắc bênh là 16,6 \pm 14,6 (264) tháng, trong đó $79,6 \%$ trường hợp mắc bệnh dưới hai tuổi. Tî lê mắc bênh trẻ trai/gái là $1,7: 1$. Trẻ đi ngoài phân có nhây máu chiếm $100 \%$. Các triệu chứng lâm sàng thường găp là chán ăn $79,7 \%$, sốt $76,6 \%$, mất nước $35,9 \%$, đau bụng $35,9 \%$ và nôn $34,4 \%$. Các triêu chứng khác kèm theo như hâu môn sưng đỏ 45,3\%, mót rặn khi đi ngoài $40,6 \%$, thiếu máu $37,5 \%$ và bunng chướng $18,8 \%$. Xét nghiêm máu có tăng bach cầu, tăng CRP, hạ Kali, hạ Natri với tỷ lệ lần lượt là $54,7 \%, 70,3 \%, 17,1 \%, 1,6 \%$. Tỷ lệ bạch câu, hồng câu trong phân là $100 \%$ và $78,1 \%$. Cấy phân có Salmonella chiếm 4,7\%. Kết luân: Trẻ tiêu chảy cấp phân máu thường có biểu hiện chán ăn, sốt, hậu môn sưng đỏ, mót rặn khi đi ngoài. Xét nghiệm máu thường gặp tăng bạch câu và CRP. Tỷ lệ phát hiện vi khuẩn qua nuôi cấy phân thấp. khuẩn

Tír khóa: Tiêu chảy cấp phân máu, trẻ em, nhiễm

\section{SUMMARY}

CLINICAL AND LABORATORY CHARACTERISTICS OF ACUTE BLOODY DIARRHEA IN CHILDREN AT THE DUC

${ }^{1}$ Trường Đại học Y Hà Nội

Chịu trách nhiệm chính: Nguyễn Thị Việt Hà

Email: vietha@hmu.edu.vn

Ngày nhân bài: 14.5.2021

Ngày phản biên khoa hoc: 2.7.2021

Ngày duyệt bài: 12.7.2021

\section{Nguyễn Thị Mai Hương1, Nguyễn Thị Việt Hà ${ }^{2}$} GIANG GENERAL HOSPITAL

Acute bloody diarrhea commonly is associated with pathogenic bacteria in pediatric patients, affecting the child's development. Aim: describe the clinical and laboratory characteristics of acute bloody diarrhea in young children. Materials and methods: a case series included 64 patients diagnosed with acute diarrhea stool blood in treatment at Duc Giang General Hospital from August 2020 to May 2021. Results: The mean age of patients was $16.6 \pm 14.6$ (2-64) months, of which $79.6 \%$ happened in children less than two years old. Morbidity rate of male/female is $1,7: 1$. Children with bloody mucus accounted for $100 \%$. Common clinical symptoms were anorexia $79.7 \%$, fever $76.6 \%$, dehydration $35.9 \%$, abdominal pain $35.9 \%$ and vomiting $34.4 \%$. Other accompanying symptoms such as anal swelling and redness $45.3 \%$, pain when defecating $40.6 \%$, anemia $37.5 \%$ and abdominal distension $18.8 \%$. Blood test showed increased leukocytocis and CRP, decreased Kali and Natri with the rates of $54.7 \%, 70.3 \%, 17.1 \%, 1.6 \%$, respectively. The percentage of white blood cells, red blood cells in the stool is $100 \%$ and $78.1 \%$. Fecal culture positive with Salmonella was $4.7 \%$. Conclusion: Children with bloody diarrhea often manifest of anorexia, fever, anal redness, pain when defecating. Blood tests usually show increased leukocytosis and CRP. Positive bacterial culture was low.

Keywords. Bloody diarrhea, children, infection.

\section{I. ĐăT VẤN ĐỀ}

Tiêu chảy là bệnh có tỷ lệ mắc và tử vong cao đứng hàng thứ hai ở trẻ em. Theo thống kê của Tổ chức y tế thế giới, hàng năm có 1,7 tỷ trẻ mắc tiêu chảy với 525000 trường hợp tử vong ${ }^{1}$. Nghiên cứu năm 2010 của Bùi Thị Hồng Thắm cho thấy $\mathrm{E}$. coli chiếm $18,8 \%$ trong số 32 trẻ tiêu máu từ 2 đến 6 tháng tuổi và khoảng $40 \%$ vi khuẩn phân lập được từ phân ${ }^{2}$. 53\% trường hợp tiêu chảy cấp phân máu là do E.coli ở nhóm trẻ 1 tháng đến 5 tuổi được ghi nhận bởi Nguyễn 